\title{
Improving Doctoral Success by Matching PhD Students with Supervisors
}

\author{
Martha L. Orellana \\ Universidad Autónoma de Bucaramanga, \\ Bucaramanga, Colombia \\ morellana@unab.edu.co
}

\begin{abstract}
Antònia Darder, Adolfina Pérez, and Jesús Salinas Universitat de les IIles Balears, Palma, Illes Balears, Spain

antonia.darder@uib.es; fina.perez@uib.es; jesus.salinas@uib.es
\end{abstract}

\begin{abstract}
A key aspect of the effective supervision of $\mathrm{PhD}$ research is the supervisor-student relationship. This interaction is affected by the characteristics and needs of students and institutional conditions, as well as the skills, attitudes, and roles of supervisors and their supervisory styles. When supervision is carried out at a distance, it entails an additional challenge, mainly concerning interaction. The purpose of this study is to improve the research process, supervision, and design of virtual environments in order to support this supervision. The study identifies the supervisory relationships that affect doctoral research conducted at a distance from the student's academic institution. It also describes how students and their supervisors perceived the characteristics of supervision and the skills and attitudes students perceived in and expected from their supervisors. For data collection, semistructured interviews were used. The results indicate important differences between supervisors' perceptions concerning their own role and students' needs regarding supervision, and they demonstrate the importance of attending to student needs and, on the part of supervisors, exercising responsibility in the development of research competencies in students, as is the case of independence of criteria and autonomy.
\end{abstract}

Keywords: postgraduate research supervision, distance supervision, $\mathrm{PhD}$ supervision, supervisory styles, supervisor attitudes and roles, supervisor-student relationship

\section{Introduction}

Advances in technology are leading to new possibilities for the access and availability of $\mathrm{PhD}$

Material published as part of this publication, either on-line or in print, is copyrighted by the Informing Science Institute.

Permission to make digital or paper copy of part or all of these works for personal or classroom use is granted without fee provided that the copies are not made or distributed for profit or commercial advantage AND that copies 1) bear this notice in full and 2) give the full citation on the first page. It is permissible to abstract these works so long as credit is given. To copy in all other cases or to republish or to post on a server or to redistribute to lists requires specific permission and payment of a fee. Contact Publisher@InformingScience.org to request redistribution permission. studies and, above all, to profound changes in the way relationships between supervisors and students are established during postgraduate research, especially when these relationships are conducted at a distance.

One of the most sensitive aspects of the development and successful completion of distance postgraduate research is the support and guidance received from 
supervisors (Jones, 2013). As far as the supervisor's role is concerned, this guidance varies according to the supervisor's profile and the stage of the research as well as the student's profile and needs. Hence, different supervisory roles and different models of supervision can be identified.

The present study addresses a particular dynamic of supervision in which supervisor and student use online communication systems instead of meeting face-to-face. Online postgraduate research works in a different way than face-to-face supervision because it presents greater difficulties and requires changes in supervisory roles. Several authors, including Price and Money (2002), Macauley (2002), and Hartikainen, Suhonen, and Sutinen (2006), have pointed out these difficulties.

This study focuses on Spanish doctoral programs in education sciences in which Latin American students participate. Although several doctoral-program formats exist in Spain, almost all the cases investigated here belong to the training phase, usually two years long, and the research phase, in which students develop the thesis. The students in these doctoral programs are characterized by their internationalization, mature age, and part-time status, and because they are conducting the research stage at a distance they have not completely abandoned their obligations to their academic institution.

This type of distance $\mathrm{PhD}$ student usually relies heavily on systems and environments that enable communication management - such as virtual learning environments - and online communication tools - such as e-mail and videoconferencing. Thus, the communication space itself conditions the specific elements of the supervisor-student relationship. This study analyzes the elements of supervisory style and, alongside this, the supervisor's skills, both of which are key in a distance context.

\section{Literature Review}

A key factor of the success of a research project is the relationship between the supervisor and researcher during the training stage. This relationship is influenced by a variety of factors, among which are the characteristics of both supervisor and student (including interests, experiences, and prior knowledge at the onset of the research), supervisor roles, and supervisory styles. Effective supervision of researchers during the training stage is a multifactorial process that involves not only issues such as the relationship between students and supervisors at all levels, but also the infrastructure available, institutional and government policies, structures, and procedures (Abiddin, Ismail, \& Ismail, 2011; Green, 2005; Holbrook et al., 2014; Jiranek, 2010; Jones, 2013).

\section{Weaknesses of Postgraduate Programs and Factors that Affect their Successful Completion}

Researchers have identified the following as significant predictors of completion of the postgraduate research project: degree of attendance (part- or full-time), availability of research funding, age, excellence of prior academic record, discipline (sciences or arts), gender, suitability of the research topic, intellectual environment of the department, and access to appropriate equipment and to computers (Bourke, Holbrook, Lovat, \& Farley, 2004; Jones, 2013; Latona \& Browne, 2001; Lee, 2008; Pearson \& Brew, 2002; Rodwell \& Neumann, 2007).

Love (2001) identified the following as the main weaknesses of doctoral programs based on traditional models:

- A large number of students do not complete the program.

- The directors of research projects often do not know whether a researcher in training needs additional support for the completion of the program. 
- The syllabi of many such postgraduate programs emphasize the acquisition of skills that may be of little use to their students.

- The teaching process associated with the acquisition of research competencies and knowledge is itself weak.

In addition to the elements that affect the success or completion of the program, these weaknesses must be taken into account in supervision practice. According to Edwards (2002), moreover, there exist four significant problems in the postgraduate experience: (1) clashes between the purposes of supervisors and students, (2) lack of support structures for students, (3) student isolation, and (4) student confusion regarding the function of resources.

Along these lines, a frequently investigated issue is the quality of supervisory practices and its demonstrable effect on the completion of the PhD (Ali \& Kohun, 2007; Cullen, Pearson, Sasha, \& Spear, 1994; Dinham \& Scott, 1999; Golde, 2005; Green, 2005; Lee, 2008; Lee \& Boud, 2009; McCallin \& Nayar, 2012; Vilkinas, 2007; Wikeley \& Muschamp, 2004). Concerning the quality of these practices, Dinham and Scott $(1999$, p. 2$)$ underlined the importance of supervisor-student interaction and observed that "the student-supervisor relationship has the potential to be marvelously enriching and productive, but may also be extremely difficult and personally devastating."

The skills of the supervisor represent another factor that may influence the successful completion of research projects.

\section{Effective Supervisory Roles and Styles}

Many studies have identified the style, roles, and abilities of the supervisor as key factors of the success of PhD candidates (Brown \& Atkins, 1988; Buttery, Richter, \& Filho, 2005; Cullen et al., 1994; Latona \& Browne, 2001; Pearson \& Brew, 2002; Quinn, 1988; Taylor \& Beasley, 2005; Vilkinas, 2007; Vilkinas \& Cartan, 2001, 2006).

In this study, roles are defined as the functions and tasks involved in the supervisory process; supervision styles are defined as the approaches supervisors adopt for their interventions, which may vary during the supervisory process and in which different roles are combined with different degrees of intensity; and skills and competencies are defined as requirements for supervisors' ideal performance of their diverse roles.

Brown and Atkins (1988), in a now-classic study, suggested that effective supervisors must be competent researchers, must be able to reflect this competence in research practices, and must be able to analyze the knowledge, techniques, and methods that make their supervision effective. Moreover, Abiddin, Ismail, and Ismail (2011), in their investigation of clinical supervision, mentioned the following four skills that, according to Wilkin, Bowers, and Monk (1997), a supervisor requires: (1) communication skills, which include an ability both to listen and to make comments in an open, objective, and constructive way; (2) support-oriented skills, which involve an ability to identify at what moment a student needs help and to offer the appropriate support; (3) general skills; and (4) skills specific to the student's field of research.

Another important factor is the type of leadership carried out by the supervisor. According to Frischer and Larsson (2000), there are three patterns of leadership: democratic, authoritarian, and laissez-faire.

Cullen et al. (1994) organized the indicators of the effective management of research projects into four main categories.

1) Effective supervisory style is reflected in the skill of direction and leadership; organization of regular meetings; making time to enable students to develop original ideas; flexibility in project choice; encouraging ideas and individuality; and to a lesser extent, pro- 
moting close interaction with other academics, attendance at conferences, and publishing before completion of the research project.

2) Effective supervisor competence with respect to the student's project is reflected in scientific competence, familiarity with the relevant academic literature, expertise in the area of the project, and awareness of science overseas.

3) Effective supervisor attitudinal characteristics are reflected in approachability and friendliness, being supportive and positive, being open-minded and willing to recognize errors, being organized and stimulating, and transmitting enthusiasm. Other important characteristics may be political compatibility with the student and a lack of obsession with wealth and recognition.

4) Effective academic and intellectual standing is reflected in the supervisor's ability to be a creative, flexible thinker, intellectual excellence, consistent participation in his or her own research, good publication record, engagement in searches for external funding, and to a lesser extent, professional interaction and influence in the department.

Other researchers have supported these categories in recent years (Bøgelund, 2015; Egan, Stockley, Brouwer, Tripp, \& Stechyson, 2009; Holbrook et al., 2014; Taylor \& Beasley, 2005; Zhao, 2003; Zuber-Skerrit \& Roche, 2004).

Lee (2007) attempted to help supervisors see the $\mathrm{PhD}$ as a source of important research skills. In order to maintain a balance between the tensions arising (concerning developing competencies for employment and for research, and completing the thesis on time; or regarding the process and the product), she proposed a model with five supervisory approaches: functional (progress through tasks, which requires the supervisor to direct and manage projects), critical thinking (constant questioning of the student, which requires reasoning and analysis on the part of the supervisor), enculturation into the institution and the disciplinary community (which requires the supervisor's coaching), emancipation/mentoring related to the student's professional growth (which requires the supervisor's reflection and granting of empowerment), and, lastly, development of quality relationships (which requires the supervisor to support the development of emotional intelligence in the student). Moreover, Lee (2007) established relationships between these approaches and the four categories identified by Brew (2001) as a different way in which research can be conceptualized by supervisors and students.

- Director (determining topic and method, providing ideas)

- Facilitator (providing access to resources or expertise, arranging field-work)

- Adviser (helping to resolve technical problems, suggesting alternatives)

- Teacher (of research techniques)

- Guide (suggesting timetable for writing up, giving feedback on progress, identifying critical path for data collection)

- Critic (of design of enquiry, of draft chapters, of interpretations of data)

- Freedom giver (authorizes student to make decisions, supports student's decisions)

- Supporter (gives encouragement, shows interest, discusses student's ideas)

- Friend (extends interest and concern to non-academic aspects of student's life)

- Manager (checks progress regularly, monitors study, gives systematic feedback, plans work)

- Examiner (e.g., internal examiner, mock vivas, interim progress reports, supervisory board member)

\section{Figure 1. Supervisor roles (Brown \& Atkins 1988, p. 120)}

Brown and Atkins (1988, p. 120) proposed a list of supervisor roles and attitudes that incorporates 11 roles a supervisor may play (Figure 1). 
Supervisory styles, roles, and attitudes are related to the tasks of a supervisor. Pearson and Kayrooz (2004) categorized the tasks and responsibilities of supervision into four groups: those related to the progress of the candidate, mentoring (personal and professional support, including the connection of the student with research networks, both academic and professional), coaching in the research topic, research methodology, and how to write the dissertation, and sponsorship of the student's participation in academic or professional practice (via access to technical and financial resources and to learning and research opportunities). Lee (2007) suggested that this classification of a supervisor's tasks and responsibilities is associated with one of the five approaches in her proposal: the emancipation/mentoring approach, which helps the student move from being dependent to being self-directed and emphasizes that the aim of this process is the application of experience and the development of skills for critical thinking.

This conceptualization of supervisory styles has been supported by different models, and, although it takes doctoral students' profiles into account, the focus is on the supervisor's role. Recent years have witnessed an evolution of these models from Gurr's (2001) dynamic model or Gatfield's (2005) dynamic conceptual model to either the integrated competing values framework (Vilkinas, 2008), the model for interpersonal supervisor behavior (Mainhard, van der Rijst, van Tartwijk, \& Wubbels, 2009), or the framework of approaches to research supervision (Lee, 2008, 2012). These models, which have some characteristics in common, present evolutionary differences ranging from relatively static conceptions to more dynamic perspectives.

Gurr (2001) elaborated on B. Grant's (1999) metaphor of the "rackety bridge" and designed a dynamic model for the alignment of supervisory style with the trainee researchers' development of "competent autonomy." Gurr's model is defined by two key dimensions, a direct/indirect dimension, referring to the supervisor's intervention, and an active/passive dimension, referring to the student's participation, which form a matrix with four categories of conduct (Figure 2). A central point is that the effective supervisor moves flexibly between the different modes. Most notably, the candidate progresses from dependence to competent autonomy. This form of adaptive commutation may even take place within the space of a single meeting.

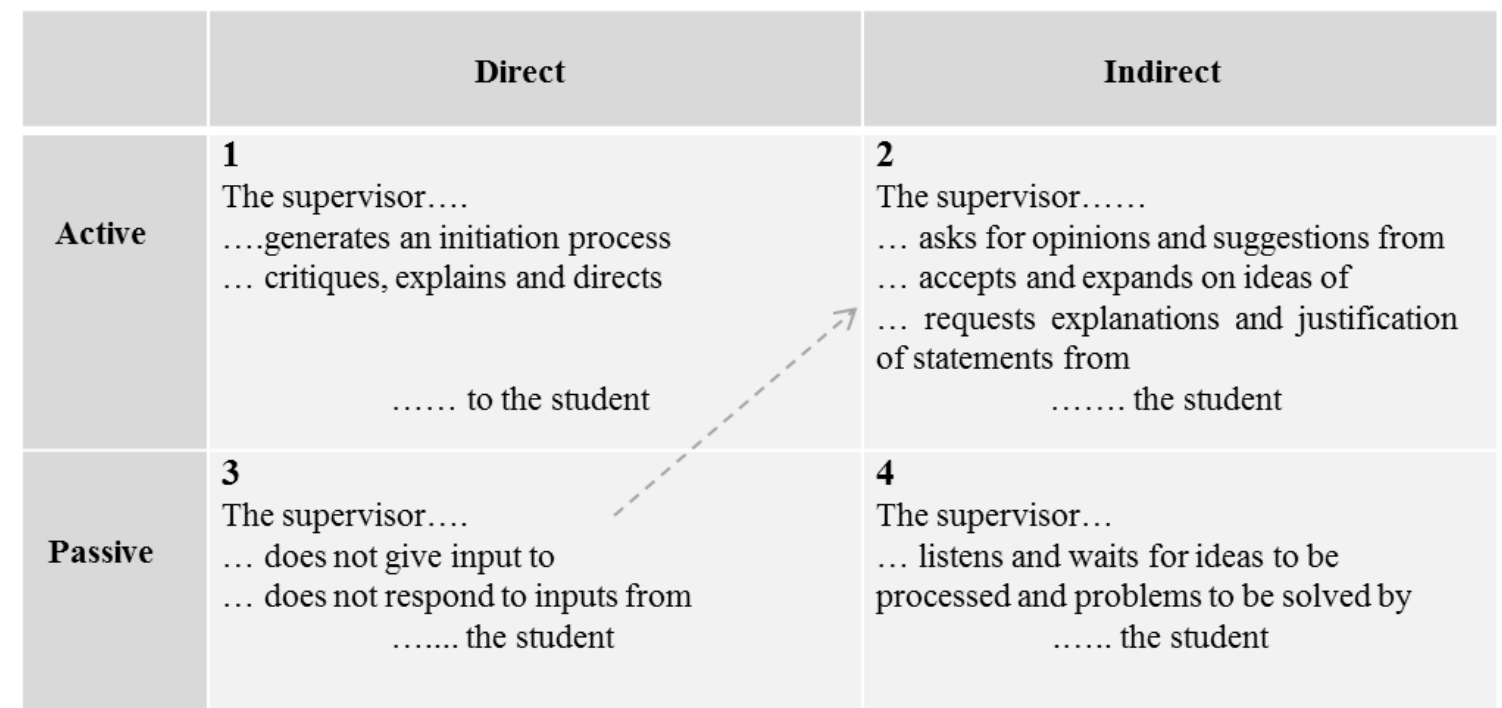

Figure 2. Alignment of supervisory style and student autonomy (adapted from Gurr, 2001)

Gatfield (2005), in turn, proposed a model of supervisory styles based on two dimensions: the structural, directive, and organizational dimension and the supporting dimension, which is nondirective and comprises support, interaction, and feedback. 
Likewise, Mainhard et al. (2009) suggested that when people interact over a period of time, patterns such as personal styles can be identified in the relationship; these patterns depend on the behavior of both parties of the interaction. Consequently, the same person may exhibit different styles depending on the person with whom they are interacting. Their model describes the behavior of supervisors with respect to their relationships with students, which is based on the two dimensions of influence and closeness.

Moreover, Armitage (2007) proposed a model of supervisory styles in which supervisory roles change depending on the style of the supervisor at any given time, with supervisors moving between two opposite dimensions: one is a task-focused dimension in which they play the role of expert and director, and the other is a process-focused, nondirective dimension in which they play the role of enabler, a role that becomes increasingly dominant as the relationship between supervisor and student progresses.

Brew (2001) highlighted the importance supervision may have and the conceptions of researchers themselves concerning the nature of research. On the one hand, they argued, a clear conception of what research is provides a basis on which to understand other such conceptions; on the other hand, differences between students' and supervisors' conceptions of research may illuminate the difficulties of completing postgraduate degrees due to an incompatibility between student and supervisor conceptions. Brew established a framework with four categories: "domino" (a process in which separate elements are synthesized in order to solve problems), "layer" (a process in which hidden or underlying meanings are discovered or created, "trading" (a sort of social market that features the exchange of products such as publications and the participation in social networks that grant personal recognition), and "journey" (a personal journey of discovery that can give rise to transformation and that links existential questions and personal dilemmas through the researcher's awareness of his or her career).

Vilkinas and Cartan (2001) presented a competing values model that focuses on the management of the process, which is framed in two dimensions: internal-external focus and flexibilitystability. To the eight model roles of Quinn (1988); (innovator, broker, producer, director, coordinator, monitor, facilitator, and mentor) they add a ninth role: that of integrator. Vilkinas and Car$\tan (2006)$ and Vilkinas (2007) simplified this model by reducing the roles to five (developer, innovator, broker, monitor/distributor, and integrator), based in this case on two dimensions: internal/external focus, person-focused/task-focused.

In distance supervision, the context of the present study, the practice of supervision and the supervisor-student relationship take on greater importance because students feel isolated, and thus the need for a means of overcoming the problems associated with these two aspects arises (Hartikainen, Suhonen, and Sutinen 2006; Macauley 2002). Thus, this study aims to identify the perceptions and expectations of students and their supervisors concerning research supervision in distance contexts.

With respect to the purposes of the study and the design of the data-gathering instrument, although each of the approaches and models outlined above can be considered representative of the supervisory styles and of the work carried out by supervisors, we opted for a model that can reflect styles of supervision using flexible frameworks and variables of supervisory action and that is based mainly on two dimensions, one that is more directive and the other less directive. We therefore opted for the model developed by Gurr (2001). With respect to the roles of the supervisor, we decided on a model that offers a broad list of roles encompassing the proposals of different authors. Hence, we opted for the list of roles proposed by Brown and Atkins (1988), suppressing its last option, as do Cullen et al. (1994, p.101), because it does not apply to Spanish doctoral programs, in which no partial assessments are conducted during the dissertation-production process. 


\section{Method}

\section{Purpose of the Study}

Because it is challenging - for both supervisors and students - to adapt to the research environment associated with distance supervision, this study explores the nature of the supervision relationships that emerge in this context.

The study investigates a specific type of student: one who conducts doctoral research on a parttime basis and mainly at a distance. This form of study involves a dynamic of supervision in which online communication systems are used because supervisor and student do not normally meet face-to-face.

The aim of the study is to identify supervisory elements in order to improve both the research process and online supervision, and it considers both the supervisor's and student's perspectives. It is an exploratory study that addresses the following questions: (1) How is such supervision carried out in practice? (2) What styles characterize this supervision, and what are the skills and attitudes perceived by supervisors? and (3) What skills and attitudes do students look for in a supervisor in this context?

\section{Participants}

The participants consisted of an intentional stratified sample of tandem supervisor-doctoral student cases, whose relationships were conducted mainly online. The supervisors were chosen by considering the type of doctoral program, and the students were then chosen based on the cases suggested by the supervisors.

In the confirmation of the sample, we initially identified 42 doctoral programs in education sciences offered by Spanish universities, in which research supervision could potentially be conducted online. Considering the type of $\mathrm{PhD}$ program a relevant variable, we invited 23 supervisors from 16 institutions to participate in the interviews, all of them professors in PhD programs in education who supervised students who had conducted their $\mathrm{PhD}$ research from places remote from the institution. We conducted a total of 14 interviews with supervisors. The rest of the cases did not meet the conditions of online supervising or did not involve a dissertation completed during 2010-2012, or the supervisor did not respond to the invitation to participate. Each of the supervisors was asked to contact one or two of their supervised students who had most recently completed their research and whose doctoral thesis had been evaluated between 2010 and 2012 . We conducted a total of 12 interviews with students.

The distribution of the initial and final samples of supervisors and students is represented in Table 1.

Table 1. Stratified sample for the interviews.

\begin{tabular}{cccccc}
\hline & \multicolumn{2}{c}{ Supervisor sample } & \multicolumn{2}{c}{ Student sample } & TOTAL \\
Type of PhD program & Initial & Final & Initial & Final & interviewed \\
\hline $\begin{array}{c}\text { Specific agreement between two institu- } \\
\text { tions (Spanish and Latin American) } \\
\text { International Inter-university }\end{array}$ & 8 & 7 & 7 & 6 & 13 \\
$\begin{array}{c}\text { National Inter-university (admitting for- } \\
\text { eign students) }\end{array}$ & 5 & 3 & 3 & 3 & 2 \\
$\begin{array}{c}\text { Conventional from a single university } \\
\text { (admitting foreign students) }\end{array}$ & 6 & 3 & 3 & 2 & 6 \\
\hline TOTAL & 23 & 14 & 14 & 12 & 26 \\
\hline
\end{tabular}


The supervisors interviewed can be characterized as follows:

- Teachers with experience instructing postgraduate students in online learning environments

- Senior supervisors in online processes (between 5 and 20 years of experience, and between 3 and $18 \mathrm{PhD}$ dissertations supervised either partially or wholly online, with a resulting mean of greater than 8 cases of supervision)

The students interviewed can be characterized as follows:

- Part-time $\mathrm{PhD}$ students (10 of the 12 cases)

- Residents of Latin American countries: Venezuela (4), Chile (3), Argentina (1), Brazil (1), Mexico (1), The Dominican Republic (1), and Italy (1)

- Supervised in the period 2006-2012 and PhD dissertation completed in the period 2010 2012

- Mostly university lecturers (11 of the 12 cases)

- Short stays at the home university of the $\mathrm{PhD}$ program

- Motivation for completing $\mathrm{PhD}$ program: gaining promotion as a university lecturer (11 of the 12 cases) and/or personal growth or a desire to follow a career in research (9 cases) and program belonging to the institution itself for this promotion ( 6 cases)

\section{Data Collection and Processing}

The semistructured interview was used as the method for collecting information because it is one of the most appropriate methods for exploratory studies of this type and because it is an efficient way to collect rich data and to contribute to the understanding of a phenomenon. In this case, the method turned out to be extremely useful for understanding the way senior researchers carry out the online supervision of doctoral research and the dynamics of their work.

The semistructured interviews consisted of an initial open conversational interview and a second interview in which some closed questions were added - especially for sorting or rating statements and for items that emerged from the thematic analysis - and conducted by way of confirmation or conclusion, involving individuals in reflection in order to ensure that the key areas of interest in the study were covered at the same time as obtaining valuable information regarding the interviewees' spontaneity (Vilkinas, 2008).

The procedure for this performance included the necessary indications for its development, taking into consideration both previous formalities and interview contents in order to help the interviewer. Interviews were conducted while the interviewees were in their own countries; videoconferencing systems were used, and the audio was recorded.

A script of questions was not used, although the interviewer did have a suggested item list in case questions did not arise spontaneously. Furthermore, some tools previously prepared to sort/rate the statements were made available (Figures 1 and 2 were presented on the screen at the end of the interviews). This part was the most structured.

Although a review of the literature was considered, a category system was not developed prior to the interviews. However, before starting the line-by-line analysis, we established the data-analysis categories in view of the thematic analysis from the interviews. Afterwards, the categories were applied to the interview transcriptions. 


\section{Results}

To address the challenges presented by online supervision and to support improvements in the process of doctoral research in this context, it was considered important to obtain in-depth knowledge of all the supervisory styles and supervisor skills involved in each case of online supervision as well as of the way in which the supervisory process was conducted.

Concerning the information obtained through the interviews, the main interest was any reference to the qualities, attitudes, and styles of supervision exhibited by supervisors and to the qualities considered to be desirable in supervisors, from the point of view of both students and supervisors.

\section{Supervisory Styles Perceived in Relation to Supervision}

One of the most interesting aspects of the supervisory relationship is the autonomy and independence of the student in the process. Another is the assessment made of this aspect by both supervisors and students, based on their experience of the supervisory relationship.

Student autonomy in the process was mentioned by 13 of the 14 supervisors and 10 of the 12 students. On 5 and 8 occasions, respectively, independence of criteria was mentioned by students. Students felt they could discuss their ideas with their supervisors. The supervisors offered some very important assessments regarding independence of criteria. Supervisor 3 said, "The student is independent, the research is theirs" and "We discussed the questions at the student's request"; Supervisor 8 said, "I transmit to the students what I do as a researcher" and "There is autonomy and trust"; and Supervisor 11 said, "They have independence of criteria as I consider them to be researchers already." However, some supervisors expressed certain reservations. Supervisor 1 said, "The student has autonomy, but not independence from the lines of work of the research group"; and Supervisor 5 said, "In the first stages I accompany, afterwards they are more independent" and "The students are very autonomous, even too much so, sometimes creating problems."

At a certain point in the interview, the supervisors were asked to place themselves in one of the squares of the dynamic model designed by Gurr (2001), which, as noted above, was adopted for this study. They were shown the matrix presented in Figure 2. The students were asked to place their supervisors in the same matrix, according to the style of direction they considered predominant.

The results show a high degree of correspondence between the perceptions of students and their supervisors, with the supervisors in their research process being placed in square 2 of the aforementioned model, as shown in Table 2.

Table 2. Perception of supervisory styles according to students and their supervisors, using the matrix of Gurr's (2001) model.

\begin{tabular}{ccc}
\hline Student participation & Direct intervention & Indirect intervention \\
\hline \multirow{2}{*}{ Active } & $\mathbf{Q 1}$ & $\mathbf{Q 2}$ \\
& $\mathrm{Sup}=4$ & $\mathrm{Sup}=10$ \\
& $\mathrm{St}=0$ & $\mathrm{St}=10$ \\
& $\mathbf{Q 3}$ & $\mathbf{Q 4}$ \\
Passive & $\mathrm{Sup}=0$ & $\mathrm{Sup}=0$ \\
& $\mathrm{St}=0$ & $\mathrm{St}=2$ \\
\hline
\end{tabular}




\section{Skills and Attitudes of Supervisors Perceived in the Supervisory Relationship}

To analyze the views of students and their supervisors regarding the skills and personal and professional attitudes of the supervisor, an adaptation of the relationship of roles proposed by Brown and Atkins (1988), as presented in Figure 1, was used.

Students and supervisors were asked to rank, from 5 to 1 , what they considered the 5 most important roles out of the 10 on the suggested list (Figure 1), which best represented the figure of the supervisor from their experience of the supervisory relationship. This ranking allowed some discrepancies between supervisors and students to appear.

Students perceived their supervisor, as can be seen in Table 3, first of all as a facilitator (one who provides access to resources or experience and supports the organization of fieldwork), secondarily as a teacher (an instructor of research techniques), thirdly as a supporter (one who encourages the student and shows interest in and discusses the student's ideas), and fourthly as a manager (one who checks the progress regularly, monitors study, offers systematic feedback, and helps plan the work).

The supervisors, as shown in Table 3, consider themselves first of all a critic (one who evaluates the research design, drafts of chapters, interpretations, and data), secondarily a freedom giver (one who gives the student freedom to make decisions and supports the student's decisions), thirdly a supporter (one who encourages the student and shows interest in and discusses the student's ideas), and fourthly a director (one who determines the topic and the method and provides ideas).

Table 3. Perception of attitudes and roles of the supervisor according to students and their supervisors, using a list of roles adapted from Brown and Atkins' (1988: 120) proposal.

\begin{tabular}{lcc}
\hline Roles & Supervisor & Student \\
\hline Director & $\mathbf{2 . 0 0}$ & 1.00 \\
Facilitator & 1.14 & $\mathbf{2 . 8 3}$ \\
Adviser & 1.36 & 0.58 \\
Teacher & 1.14 & $\mathbf{2 . 1 7}$ \\
Guide & 1.14 & 1.17 \\
Critic & $\mathbf{2 . 0 7}$ & 0.92 \\
Freedom giver & $\mathbf{2 . 0 7}$ & 1.42 \\
Supporter & $\mathbf{2 . 0 0}$ & $\mathbf{1 . 8 3}$ \\
Friend & 0.57 & 1.43 \\
Manager & 1.29 & $\mathbf{1 . 5 8}$ \\
\hline
\end{tabular}

The correspondences and, particularly, the differences between the perceptions of students and supervisors are clearly evident in Figure 3. What students perceived as the main roles played by their supervisor, differ significantly from supervisors' perception of their own role. 


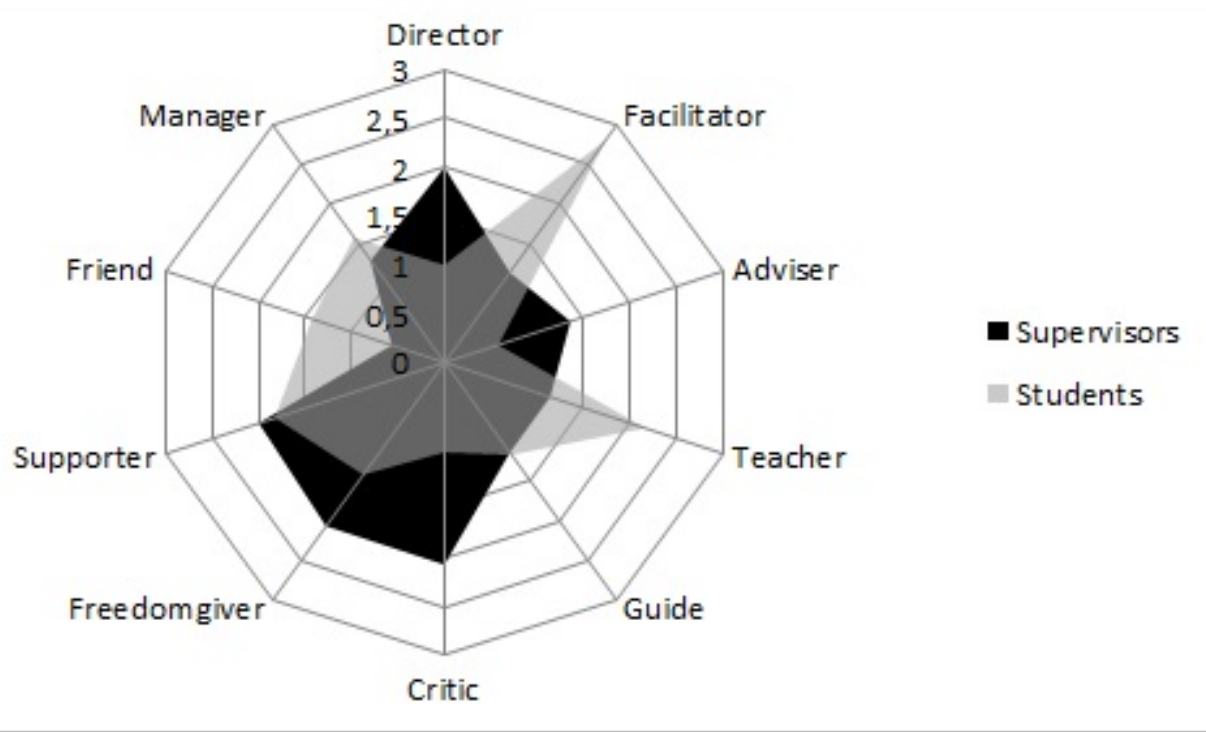

Figure 3. Perceptions of the attitudes and roles of the supervisor according to students and their supervisors, using a list of roles adapted from Brown and Atkins' $(1988$, p. 120) proposal.

\section{What Students Look for in a Supervisor}

With respect to the characteristics of an ideal supervisory relationship, whether they were identified spontaneously by the interviewee or at the interviewer's request, it can be deduced that as suggested by Gurr (2001), a supervisor may adopt different styles according to the stage of the research or according to the student's needs.

Particularly among students, "accessibility, friendliness, empathy" as well as "direction" or "expertise in the field" were considered desirable characteristics of supervisors. "Accessibility, friendliness, empathy" were mentioned by eight students, "direction" by seven, "expertise in the field" and "organization of the work" by six, with some students coinciding in several of these assessments. For example, Student 5 stated, "Who guides, who sets the way. . . . A referent," "It is important to know their point of view," "Support in the research . . . who gives a lot of moral support," and "who gave me the freedom to decide"; and Student 6 stated, "Expertise in the line of research," "Time and availability is important," and "Exerted a lot of pressure."

In the case of the supervisors, something similar happened. Of the 14 interviewees, 10 believed students seek in them "an attitude of support," eight believed they seek "expertise in the field," whereas both "direction" and "organization of the work" were mentioned by seven supervisors.

\section{Discussion}

Students and supervisors coincide in the identification of the supervisory style as one of indirect intervention that seeks to establish the autonomy of the student (Table 2), as Gurr (2001) and Taylor and Beasley (2005) demonstrated. They differ, however, in their perceptions of the supervisor's personal and professional roles and attitudes.

Figure 4 presents a comparison between the two types of results obtained: (1) how students and their supervisors perceive the supervisor, and (2) students' and their supervisors' opinions regarding what students look for in their supervisors.

Regarding the perceptions based on the experience of the $\mathrm{PhD}$ research process, whereas the students highlighted the attitude of facilitator (2.83), followed by teacher (2.17) and supporter (1.83), 
the supervisors saw their work and attitude in the process as a critic (2.07) and freedom giver (2.07), closely followed by supporter and director (2.00).
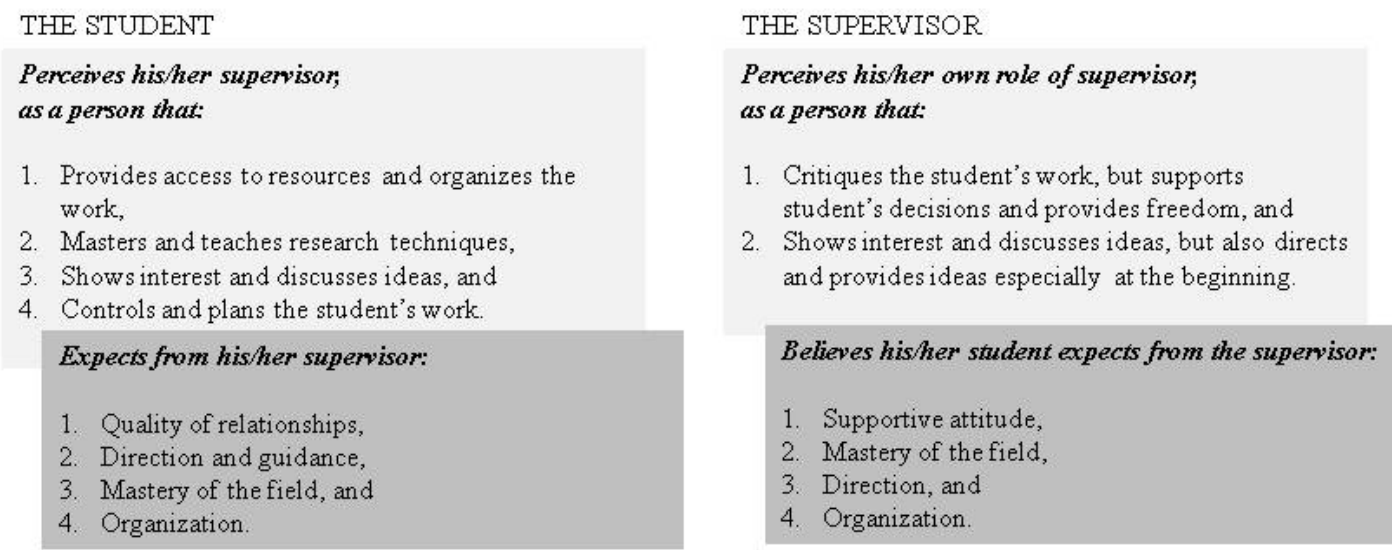

Figure 4. Perceptions and expectations of supervision according to students and their supervisors

As Figure 4 shows, students' perceptions differ from their expectations. The students seek interaction and accompaniment, guidance, support in learning, and organization. This demonstrates their need for structure and organization in their research process; on the other hand, the need for autonomy does not stand out among their needs. This result is consistent with studies by Holbrook et al. (2014) and K. Grant, Hackney, and Edgar (2014) or Woolderink, Putnik, van der Boom, and Klabbers (2015).

The way supervisors perceive their role also differs from what they believe their students are seeking in them. Whereas they perceive their role as that of a critic and that of a freedom giver, they believe students seek support, direction, and organization. This reveals that in the search for student autonomy as a researcher, supervisors recognize the student's needs, but the attitudes that as supervisors can help their students to develop independence of criteria and to progress from dependence to competent autonomy, are favored, as suggested by Gurr (2001) and Lee (2007). Students' needs must be met, but at the same time it is essential for supervisors to take responsibility for the development of research competencies in the student, as suggested by K. Grant et al. (2014). This explains why, even though a supervisor may identify with the prevailing style of supervision, that is, indirect intervention in the search for student autonomy, in practice they adopt various styles during the process, which may depend on the needs of the student (Mainhard et al., 2009) as well as on the stage of research and the particular circumstances of the student (Bøgelund, 2015; Gatfield, 2005; Kandiko \& Kinchin, 2010), aspects also evidenced during the interviews. The supervisors' perceptions also reveal that the supervisor-student relationship matures over the course of the process, to such an extent that in some of the cases student and supervisor became colleagues and began to conduct research together.

The results of the study suggest that concentrating on the supervisory style and on the roles of the supervisor should not be considered the key. It seems impractical to reduce the analysis to the pairwise relationship of supervisor-student, where the latter is considered a novice who is embarking on the difficult process of acquiring complex knowledge, a process orchestrated and directed by the supervisor's knowledge, without focusing on the abilities that the student brings to the project and on their interests and needs.

Supervision is a form of teaching and should not be seen as an exercise separate from the teaching of courses (Khene, 2014; Lee, 2007). All the supervisors we interviewed see their main role as teachers of research topics; only nine consider that they are also training their students in re- 
search, and four of these believe they are conducting research with their students (or that the student is participating in their research).

Postgraduate research supervision occurs within a rapidly changing environment, and supervisors also need formal supervision training (McCallin \& Nayar, 2012). This takes on greater importance in distance supervision, on the one hand due to students' feelings of isolation and on the other hand because the interests and needs the student may have are harder for the supervisor to determine as Ray (2007), Bøgelund (2015) or Woolderink et al. (2015) found.

We consider it an achievement to have interviewed both students and their supervisors, because this enabled us to contrast and balance the information and responses from both groups.

\section{Conclusion}

This study explores the nature of online supervisory relationships from the point of view of a group of students and their supervisors. Considering the fact that the communicative advantages offered by technology create opportunities for $\mathrm{PhD}$ research supervision to be conducted at a distance, the study set out to identify the most important characteristics of effective supervision and the strategies that can support this supervision in an online learning environment.

The correspondences and, particularly, the differences between the perceptions of students and supervisors contribute to the identification of both the characteristics of postgraduate research supervision and the elements of intervention. By taking into account the needs of students and the need to support the development of their research competencies, this study has the potential to improve both the research process and online supervision, as well as the design of virtual environments that support this supervision.

The results suggest that future research should identify student needs in relation to the different stages or moments of $\mathrm{PhD}$ research and should take into account the particular profile of the student, the characteristics of effective supervision for each of these stages, and support strategies for this supervision by making the most of the communicative advantages of technology.

\section{Acknowledgements}

This paper has been developed from the project funded under Spanish Ministry of Education, Cultura and Sports: EDU2011-25499 Methodological strategies for the integration of institutional, social and personal virtual learning environments. We would like to thank all the supervisors and the students for their willingness to participate in the study.

\section{References}

Abiddin, N., Ismail, A., \& Ismail, A. (2011). Effective supervisory approach in enhancing postgraduate research studies. International Journal of Humanities and Social Science, 1(2), 206-217.

Ali, A., \& Kohun, F. (2007). Dealing with social isolation to minimize doctoral attrition - A four stage framework. International Journal of Doctoral Studies, 2, 33-49. Retrieved from http://www.ijds.org/Volume2/IJDSv2p033-049Ali28.pdf

Armitage, A. (2007). Supervisory power and postgraduate supervision. The International Journal of Management Education, 6 (2), 18-29.

Bourke, S., Holbrook, A. Lovat, T., \& Farley, P. (2004). Attrition, completion and completion times of PhD candidates. Paper presented at AARE International Education Research Conference. Melbourne November 29 - December 2: Australian Association for Research in Education (AARE). Retrieved from http://nova.newcastle.edu.au/vital/access/manager/Repository/uon:2422 
Brew, A. (2001). Conceptions of research: A phenomenographic study. Studies in Higher Education, 26(3), 271-285.

Brown, G., \& Atkins, M. (1988). Effective teaching in higher education. London: Methuen.

Bøgelund. P. (2015). How supervisors perceive PhD supervision - And how they practice it. International Journal of Doctoral Studies, 10, 39-55. Retrieved from http://ijds.org/Volume10/IJDSv10p039055Bogelund0714.pdf

Buttery, E.A., Richter, E. M., \& Filho, W. L. (2005). An overview of the elements that influence efficiency in postgraduate supervisory practice arrangements. International Journal of Education Management, 19(1), 7-26.

Cullen, D. J., Pearson, M., Sasha, L. J., \& Spear, R. H. (1994). Establishing effective PhD supervision. Canberra: Australian Government Publishing Service. Received from http://nccastaff.bournemouth.ac.uk/hncharif/MathsCGs/Desktop/PGCertificate/230 full.pdf

Dinham, S., \& Scott, C. (1999). The doctorate talking about the degree. Sydney: University of Western Sydney.

Edwards, B. (2002). Postgraduate supervision: Is having a Ph.D. enough? Paper presented at AARE: Australian Association for Research in Education Conference. Brisbane, Australia.

Egan, R., Stockley, D., Brouwer, B., Tripp, D., \& Stechyson, N. (2009). Relationships between area of academic concentration, supervisory style, student needs and best practices. Studies in Higher Education, 34(3), 337-345.

Frischer, J., \& Larsson, K. (2000). Laissez-faire in research education: An inquiry into a Swedish doctoral program. Higher Education Policy, 13, 132-155.

Gatfield, T. (2005). An investigation into PhD supervisory management styles: Development of a dynamic conceptual model and its managerial implications. Journal of Higher Education Policy and Management, 27(3) (November), 311-325. doi:10.1080/13600800500283585

Golde, C. M. (2005). The role of the department and discipline in doctoral student attrition: Lessons from four departments. Journal of Higher Education, 76(6), 669-700.

Grant, B. (1999). Walking on a rackety bridge: Mapping supervision. In Higher Education Research and Development Society of Australasia. Retrieved from http://www.herdsa.org.au/branches/vic/Cornerstones/pdf/grant.pdf

Grant, K., Hackney, R., \& Edgar, D. (2014). Postgraduate research supervision: An 'agreed' conceptual view of good practice through derived metaphors. International Journal of Doctoral Studies, 9, 43-60. Retrieved from http://ijds.org/Volume9/IJDSv9p043-060Grant0403.pdf

Green, B. (2005). Unfinished business? Subjectivity and supervision. Higher Education Research \& Development, 24(2), 151-163.

Gurr, G. M. (2001). Negotiating the 'Rackety Bridge' — A dynamic model for aligning supervisory style with research student development. Higher Education Research \& Development, 20(1) (May), 81-92. doi:10.1080/07924360120043882.

Hartikainen, E., Suhonen, J., \& Sutinen, E. (2006). IMPDET - An online PhD study program in educational technology. Paper presented atSixth IEEE International Conference on Advanced Learning Technologies (ICALT'06), 578-580. Kerkrade, The Netherlands. doi:doi.ieeecomputersociety.org/10.1109/ICALT.2006.188

Holbrook, A., Shaw, K., Scevak, J., Bourke, S., Cantwell, R., \& Budd, J. (2014). PhD candidate expectations: Exploring mismatch with experience. International Journal of Doctoral Studies, 9, 329-346. Retrieved from http://ijds.org/Volume9/IJDSv9p329-346Holbrook0575.pdf

Jiranek, V. (2010). Potential predictors of timely completion among dissertation research students at an Australian faculty of sciences. International Journal of Doctoral Studies, 5, 1-13. Retrieved from http://ijds.org/Volume5/IJDSv5p001-013Jiranek273.pdf 
Jones, M. (2013). Issues in doctoral studies - Forty years of journal discussion: Where have we been and where are we going? International Journal of Doctoral Studies, 8, 83-104. Retrieved from http://ijds.org/Volume8/IJDSv8p083-104JonesFT129.pdf

Kandiko, C., \& Kinchin, I. (2010). What is a Phd? Process versus product in PhD supervision. Paper presented at Concept Maps: Making Learning Meaningful, Proc. of the Fourth Int. Conference on Concept Mapping, 451-459. Viña del Mar, Chile: Universidad de Chile.

Khene, C. P. (2014). Supporting a humanizing pedagogy in the supervision relationship and process: A reflection in a developing country. International Journal of Doctoral Studies, 9, 73-83. Retrieved from http://ijds.org/Volume9/IJDSv9p073-083Khene0545.pdf

Latona, K., \& Browne, M. (2001). Factors associated with completion of research higher degrees. Government. Canberra, Australia: Canberra : Higher Education Division, Dept. of Education, Training and Youth Affairs.

Lee, A. (2007). Developing effective supervisors: Concepts of research supervision. South African Journal of Higher Education, 21(4), 680-693.

Lee, A. (2008). How are doctoral students supervised? Concepts of doctoral research supervision. Studies in Higher Education, 33(3) (June), 267-281. doi:10.1080/03075070802049202

Lee, A. (2012). Successful research supervision: Advising students doing research. London: Routledge

Lee, A., \& Boud D. (2009). Framing doctoral education as parctice. In D. Boud \& A. Lee (Eds.), Changing practices of doctoral education (pp. 10-25). London and New York: Routledge.

Love, T. (2001). New directions in PhDs: Online considerations. Paper presented at AARE.Australian Association for Research in Education. Retrieved from http://publications.aare.edu.au/01pap/lov01655.htm

Macauley, P. (2002). Doctoral research at a distance: are the deficits illusory? In T. Evans (Ed.), Research in distance education 5. Selected refereed papers from the 2000 research in distance education conference (pp. 64-76). Deakin University. Retrieved from http://hdl.handle.net/10536/DRO/DU:30010715

Mainhard, T., van der Rijst, R., van Tartwijk, J., \& Wubbels, T. (2009). A model for the supervisordoctoral student relationship. Higher Education, 58(3), 359-373.

McCallin, A., \& Nayar, S. (2012). Postgraduate research supervision: A critical review of current practice. Teaching in Higher Education, 17(1), 63-74.

Pearson, M., \& Brew, A. (2002). Research training and supervision development. Studies in Higher Education, 27(2), 135-150. doi:10.1080/0307507022011

Pearson, M., \& Kayrooz, C. (2004). Enabling critical reflection on research supervisory practice. International Journal for Academic Development, 9(1), 99-116.

Price, D. C., \& Money, A. H. (2002). Alternative models for doctoral mentor organisation and research supervision. Mentoring \& Tutoring: Partnership in Learning, 10(2), 127-135. doi:10.1080/1361126022000002446

Quinn, R.E. (1988). Beyond rational management: Mastering the paradoxes and competing demands of high performance. Jossey-Bass, San Francisco, CA.

Ray, S. (2007). Selecting a doctoral dissertation supervisor: Analytical hierarchy approach to the multiple criteria problem. International Journal of Doctoral Studies, 2, 23-32. Retrieved from http://www.ijds.org/Volume2/IJDSv2p023-032Ray18.pdf

Rodwell, J., \& Neumann, R. (2007). Predictors of timeliness of completion for doctoral students by attendance type: A pragmatic approach for institutions. Sydney: Macquarie Graduate School of Management. Retrieved from http://minerva.mq.edu.au:8080/vital/access/manager/Repository/mq:9939

Taylor, S., \& Beasley, N. (2005). A handbook for doctoral supervisors. London: Routledge. 
Vilkinas, T. (2007). An exploratory study of the supervision of Ph.D. Research students' theses. Innovative Higher Education, 32(5) (October 12), 297-311. doi:10.1007/s10755-007-9057-5. Retrieved from http://link.springer.com/10.1007/s10755-007-9057-5

Vilkinas, T. (2008). An exploratory study of the supervision of Ph.D. research students' theses. Innovative Higher Education, 32(5), 297-311.

Vilkinas, T., \& Cartan, G. (2001). The behavioural control room for managers: The integrator role. Leadership \& Organization Development Journal, 22(4), 175-185. doi:10.1108/01437730110395079

Vilkinas, T., \& Cartan, G. (2006). The integrated competing values framework: Its spatial configuration. Journal of Management Development, 25, 505-521.

Wikeley, F., \& Muschamp, Y. (2004). Pedagogical implications of working with doctoral students at a distance. Distance Education, 25(1), 125-142.

Woolderink, M., Putnik, K., van der Boom, H., \& Klabbers, G. (2015). The voice of PhD candidates and PhD supervisors. A qualitative exploratory study amongst $\mathrm{PhD}$ candidates and supervisors to evaluate the relational aspects of PhD supervision in the Netherlands. International Journal of Doctoral Studies, 10, 217-235. Retrieved from http://ijds.org/Volume10/IJDSv10p217-235Woolderink0852.pdf

Zhao, F. (2003). Transforming quality in research supervision: A knowledge management approach. Quality in Higher Education, 9(2), 187-197.

Zuber-Skerrit, O., \& Roche, V. (2004). A constructivist model for evaluating postgraduate supervision: A case study. Quality Assurance in Education, 12(2), 82-93.

\section{Biographies}

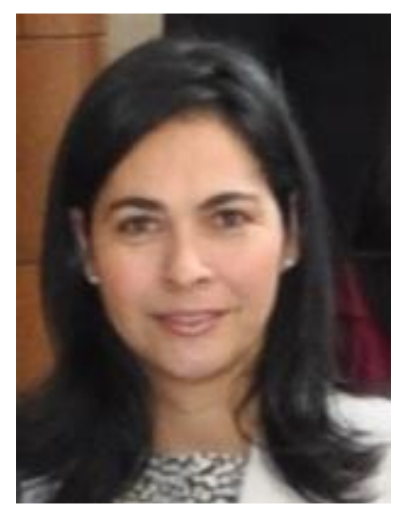

Martha Lucía Orellana is a lecturer and researcher in Educational Technology at Autonomous University of Bucaramanga (Colombia), member of the Systems Thinking Research Group in the area of education and technology. Her research interests are in postgraduate research supervision, e-learning and systems thinking.

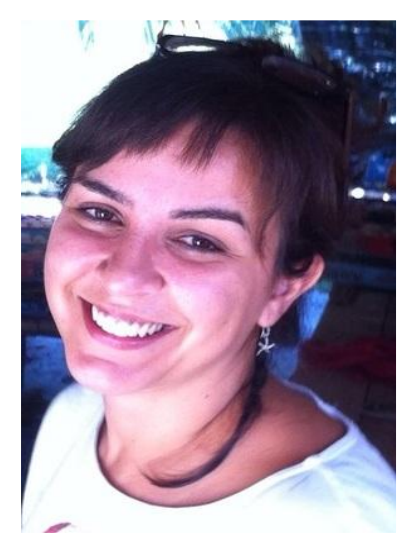

Antònia Darder is a lecturer and researcher in Educational Technology in the Department of Education of the University of Balearic Islands (Spain) and a member of the Group of Educational Technology. Her research interest focuses on distance postgraduate supervision, applications of ICT in education, and the potential of concept maps in education and research. 


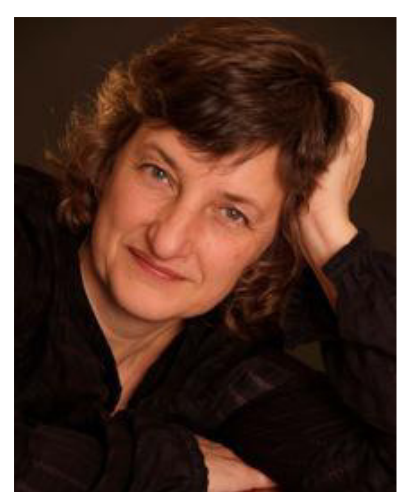

Adolfina Pérez received her $\mathrm{PhD}$ from the University of Balearic Islands (UIB). She is lecturer of Educational Technology in the Department of Applied Pedagogy and Psychology of Education of the University of Balearic Islands (Spain) and research member of the Group o Educational Technology. She is the Director of the Interuniversity Master in Educational Technology, Executive Editor of Edutec-e Electronic Journal of Educational Technology Her research interest is in integration of technology in education, design of technology educational and learning environments, and educational communication.

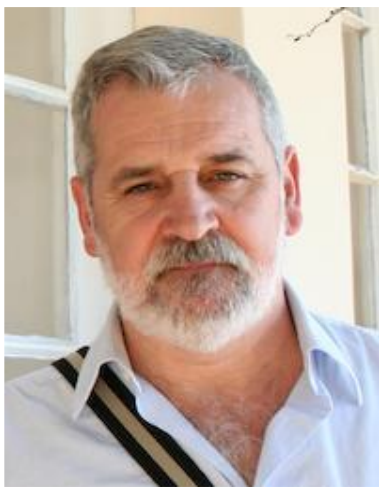

Jesus Salinas received his $\mathrm{PhD}$ from the University of Balearic Islands (UIB), Spain. He works as professor of Educational Technology at the Department of Applied Pedagogy and Psychology of Education and as a senior researcher in the Educational Technology Group. He is the Coordinator of the Interuniversity Doctorate in Educational Technology, Director of the Master of Education in Virtual Environments for the National University of Southern Patagonia (Argentina), Director of Edutec-e Electronic Journal of Educational Technology, and consultant for several universities in different countries on issues of technology integration in higher education. He received the Robert deKieffer International Fellowship Award 2006 of the AECT. His research interest includes E-

Learning, Self-Regulated E-Learning, E-Learning Design, online PhD supervision, and Personal Learning Environments. 